\section{The Impact of Managed Care on Physicians}

\author{
Mary Guptill Warren, \\ Rose Weitz, \\ and \\ Stephen Kulis
}

\section{This article investigates physicians' perceptions of how managed care has affected them, using data from a 1995 survey of A rizona physicians. Respondents report that participation in managed care has had significant and largely unpleasant effects on numerous aspects of medical practice: physician patient relationships, clinical decision making, work conditions and settings, and overall satisfaction.}

Since the 1960s, government concern about rising medical costs and declining health care coverage, coupled with corporations' recognition of the profits to be made in health care, has led to a boom in managed care. Between 1976 and 1995, the number of managed care plans nationwide increased from 175 to 591, while enrollment increased from 6 million to 51 million.' Similarly, between 1988 and 1993, the percentage of physicians with any managed care contracts increased from 61 percent to 75 percent. ${ }^{2}$ These trends are expected to continue for the foreseeable future. ${ }^{3}$

The rise of managed care has been met with much trepidation by physicians, many of whom fear that managed care will lower quality of care while reducing their income and autonomy. These fears are reflected in the comments that a surprising number of physicians took the time to write on the questionnaire described in this article. For example,

Managed care lowers quality of care, increases bureaucracy, increases physician and patient frustrations, depersonalizes the physician-patient relationship, and shifts costs but does not save money. (Specialist, 90 percent of patients from managed care contracts.)

The quality of patient care has absolutely diminished due to managed care. As a radiologist, this becomes more evident daily in dealing with these organizations. Decisions are made by elementary school dropouts routinely. (Specialist, no estimate of percentage of patients from managed care.)

Insurance companies are practicing medicine without a license albeit "bottom line" medicine which is revenue based.... [Under managed care] we will see a change from a trusting relationship with the family physician to that of an adversarial relationship as people are forced to

Key words: managed care, physicians, physician management, physician participation, physician satisfaction

Mary Guptill Warren, Ph.D., is an independent managed care consultant, Tempe, A rizona.

Rose Weitz, Ph.D., and Stephen Kulis, Ph.D., are Professors, Department of Sociology, A rizona State University, Tempe, A rizona.

The authors thank Jennie Kronenfeld, Deborah Sullivan, and Bradford Kirkmann-tiff for their help in conceptualizing this research and article. Thanks also to Joel Cantor, C.J. Hindman, Arthur Pelberg, Thomas Ross, Janine Rournain, Donald Schaller, and Shap Wolf for their suggestions on the questionnaire, and to Anthony Yeung and Anthony Mitten of the Maricopa County Medical Society for their help in boosting physician response to the questionnaire. In addition, Karen Maish and James Carvahlo provided invaluable technical assistance with the data analysis. 
go through the primary care doctor in order to see a specialist. (Primary care physician, 100 percent of patients from managed care.)

Researchers, too, often have adopted a similar stance, arguing that managed care has contributed to the "deprofessionalization " of physicians by restricting their control over the key factors that define a profession: clinical decision making, monopoly over specialized knowledge, and public trust in their motives and abilities. ${ }^{4-10}$ They note that physicians sometimes must subordinate their clinical judgment to managed care protocols, which require them to obtain approval before beginning care, restrict them to prescribing only authorized drugs, or specify the treatment plans they must follow for any given ailment. These researchers further argue that managed care threatens physicians' freedom to make everyday decisions about work conditions by pressing them to leave entrepreneurial solo practices and move into ever-larger group practices. Thus between 1983 and 1994, the proportion of physicians in solo practice fell from 40.5 percent to 29.3 percent, while the average number of physicians per group increased from 9.1 to $11.5-$ trends that are expected to continue." Finally, these researchers suggest that managed care has compromised patient loyalty and trust in physicians because physicians now often attract new patients through signing managed care contracts rather than through referrals from satisfied patients, while patients often must switch physicians simply because their employer has switched to a new plan.

Yet not all physicians share these views, even among those most affected by managed care. As another of our respondents noted on the survey form:

So, what's the point of this inquiry? Yes, my practice has changed as a result of managed care. Am I upset? No! Medicine needed to change-hopefully [now] will be the best combination possible of 1) patient satisfaction, 2) doctors satisfied with their service to patients, salary, and workload and 3) acceptable percentage of GNP spent on medical care. (Primary care physician, 100 percent of patients from managed care.)

Despite the extensive discussions about the impact of managed care on physicians, few data are available on this topic. Moreover, the available data have serious limitations. Thus Silverstein ${ }^{12}$ surveyed 300 primary care physicians to find out their perceptions of managed care, but did not compare those who do and do not participate in managed care. As a result, we cannot tell from these data what impact managed care actually has. Deckard surveyed a random sample of Florida physicians to look at the impact of working in an HMO, but only had a 37 percent response rate, making her conclusions highly unreliable.13 Hadley and Mitchell used national data to compare physicians in metropolitan areas with high versus low proportions of patients in managed care, and found that those in areas more affected by managed care worked fewer hours, saw fewer patients per week, and were slightly less likely to be very satisfied. ${ }^{14}$ Similarly, Donelan et al. compared the rate of practice problems noted by physicians in states with high versus low proportions of patients in managed care. ${ }^{15}$ Physicians in states with high managed care participation reported greater problems with paperwork, patients moving in and out of their practices because of insurance changes, patients who should have been referred for medical attention sooner, limitations on their freedom to refer patients to specialists or for diagnostic tests, financial incentives to restrict care, and pressure to see more patients than they thought appropriate.

Although these analyses tell us something about the impact of managed care on the physician marketplace in general, they do not tell us how participating in managed care affects individual physicians; we cannot tell from their analysis whether problems are greater in these areas because physicians who have more managed care patients have more problems or because those who practice in such states but do not participate in managed care have more problems. For example, are physicians in states with high managed care participation more likely to report pressure to see too many patients because those who participate in managed care are pressured by their supervisors to do so? Or because physicians in these states who do not participate in managed care fear losing market share and must aggressively seek new patients or see current patients more frequently?

\section{METHODS}

Data for this study come from a mailed survey we conducted in 1995 of a random sample of licensed physicians in active clinical practice in Maricopa County, Arizona. The sample was stratified by primary versus specialty care, and divided equally between these two groups.

We chose Maricopa County as our research site both for logistical reasons and because the rise in managed care has had a particularly strong impact there. Maricopa County is home to the city of Phoenix 
and to 59 percent of Arizona's physicians. Alone among the states, Arizona enrolls all its Medicaid-eligible residents in managed care plans (although as elsewhere, only some physicians accept Medicaid patients). In addition, 72 percent of Phoenix-area residents who have commercial health insurance are enrolled in managed care plans compared to 52.6 percent of Americans nationally." Not surprisingly, given these figures, 86 percent of Arizona physicians have at least one contract with a managed care plan. Thus, while Arizona physicians certainly do not represent physicians nationwide, their experiences can help us understand what physicians elsewhere may experience in the future.

To encourage a high response rate to our survey, each physician was sent a stamped, self-addressed envelope along with the questionnaire. The questionnaire contained both a cover letter from the researchers and a letter encouraging participation from the president of the county medical society. A second mailing and telephone follow-up calls were used to increase response rate.

A total of 510 physicians returned completed surveys, for a response rate of $\mathbf{5 1 . 5}$ percent (after removing from the sample 79 individuals who had retired, died, or moved). Our respondents do not differ significantly on demographic characteristics from Maricopa County respondents to the 1994 Arizona Board of Medical Examiners survey, which is required for licensure and answered yearly by more than 95 percent of Arizona physicians. Nor do our respondents differ greatly from physicians nationally. Men comprise 82 percent of our respondents, compared to 79 percent of physicians nationally. ${ }^{17}$ The average age of our respondents is 46 , with 81 percent under age 55, compared to 70 percent nationally..$^{17}$ Twenty-four percent of our respondents, compared to 29 percent nationally, work in solo practice. However, 51 percent work in groups of three or more, compared to only 33 percent of nonfederal physicians nationally-" An average of 11 physicians work in our respondents' practices, the same as has been found in national surveys of physicians.

Survey questions were designed to investigate the changes in the health care environment that have affected medicine as a profession in the last 20 years or so. Draft surveys were critiqued by five physicians in managed care administration (two of whom are also in clinical practice) and one who is currently moving from clinical practice to research. In addition, the draft survey was critiqued by several researchers at
Arizona State University who study either medicine as a profession or health care administration, as well as by professionals in the university's survey research laboratory. The survey instrument was pilot tested on all 21 primary care physicians contracted with a managed care plan serving Pima county (the county that includes Tucson, AZ) who attended a meeting in March 1995. Slight modifications were made to a few questions in response to physician comments.

Survey questions asked about physicians' background characteristics, practice conditions, and participation in managed care plans. To compare our respondents to the Maricopa County physician population, some questions from the 1994 County Board of Medical Examiners' physician survey were included.

Participation in managed care is measured by a question on the percentage of patients in one's practice obtained through managed care contracts. Answers to this question are divided into quartiles for the cross-tabular analysis but used as a continuous ratio variable in the regression analysis. Attitudinal items (including items about the impact of managed care) were presented as Likert-type statements, with agreement measured on a scale from 1 (strongly disagree) to 5 (strongly agree); in the data presentation, those who answer "agree" or "strongly agree" are described as agreeing. To reduce response set bias, questions were randomly phrased in a positive tone or a negative tone.

Physician satisfaction was measured by responses to three items, each measured on a scale from 1 (strongly disagree) to 5 (strongly agree). The items are: 1) I am satisfied with being a physician today; 2) If I could start again, I would still enter medicine; and 3) I am seriously thinking about leaving clinical practice. Answers to the last item were reversed so that a high value indicated satisfaction for each item. The three questions statistically loaded on one factor when entered into principal components factor analysis, with factor loadings of $\mathbf{8 1}$ or higher. The resultant factor

\footnotetext{
Our purpose in this article is not primarily to understand every factor that predicts the dependent variables ... but rather to understand the impact of one independent variable, participation in managed care, on these physician attitudes.
} 
has a high eigenvalue of 2.1. This factor score is used in bivariate correlations and regressions.

To investigate bivariate relationships between participation in managed care and categorical variables, we present cross-tabulations and chi-square tests of significance. Due to their greater statistical power, we use Pearson correlations to investigate bivariate relationships between participation in managed care and ordinal or continuous variables. None of these bivariate analyses, of course, can tell us the impact of any intervening variables. Consequently, we examine either ordinary least squares or logistic regressions (as appropriate, depending on the nature of the dependent variable) to look at the impact of participation in managed care while controlling for gender, age, size of practice, type of reimbursement, and primary care versus specialty practice. (None of the regression results shows signs of biased estimates due to multicollinearity, as indicated by variance inflation factors very close to, 1.0.)

Our purpose in this article is not primarily to understand every factor that predicts the dependent variables-physician attitudes about clinical decision making, patient-physician relationships, work conditions, or job satisfaction-but rather to understand the impact of one independent variable, participation in managed care, on these physician attitudes. Thus, whether or not managed care proves to have a strong effect in this analysis, and whether or not managed care along with the intervening variables effectively explain physician attitudes, our findings still can help us to understand the impact of managed care.

\section{RESULTS}

Almost all our respondents (91 percent) participate in some form of managed care. Seventy-nine percent participate in PPOs, 72 percent in IPA HMOs, and 44 percent in group/staff model HMOs. These categories are not mutually exclusive: most (71 percent) participate in more than one type, and 34 percent participate in all three types. Similarly, most respondents are paid in more than one way. Forty-five percent are paid according to their own fee-for-service schedule, 70 percent are paid according to a fee schedule set by third party payers, 35 percent are paid by capitation, and 40 percent are paid by salary.

The percentage of patients obtained through managed care contracts varies substantially across the sample, from 0-100 percent. Two-thirds (65 percent) of the physicians in the sample obtain half or more of their patients through managed care. Only 18 percent obtain less than a quarter of their patients through managed care, while 30 percent obtain three-quarters or more of their patients in this way.

\section{Bivariate Relationships}

\section{Physician-Patient Relationships}

Four variables were used to assess the impact of participation in managed care on physician-patient relationships. First, respondents were asked to indicate their level of agreement with the statement, "In order to get new patients, I must sign managed care contracts." Overall, 63 percent agree with the statement. Not surprisingly, agreement increases as participation in managed care increases, as indicated by a moderately strong positive correlation (Table 1).

When asked how managed care has affected their patient load, 43 percent of respondents overall claim that it has increased it, 40 percent say it has had no effect, and 17 percent say it has decreased it. Those who participate most heavily in managed care are most likely to say it has increased their patient load, while those participating least tend to report no change in patient loads.

Participation in managed care may affect not only the number of patients whom physicians see but also their relationships with patients. Physicians who participate the most in managed care are least likely to agree with the item "My patients have a great deal of confidence in physicians," as indicated by the small but significant inverse correlation.

Overall, about half of surveyed physicians (49 percent) believe that they spend much time responding to patient complaints, but participation in managed care is not related to this variable.

\section{Clinical Decision Making}

Participation in managed care also affects physicians' assessment of their clinical decision making (Table 1). Participation is negatively correlated with agreement to the statement, "Third party payers have little effect on how I treat my patients," and positively correlated with agreement to the statement, "Sometimes I must ignore my own clinical judgment and follow the directives of non-physicians regarding patient care." Overall, 32 percent agree with the former statement and 27 percent with the latter. Both these results suggest that participation in managed care limits clinical autonomy. 
BIVARIATE RELATIONSHIPS (CORRELATIONS OR CROSS TABULATIONS) BETWEEN PERCENTAGE OF PATIENTS IN MANAGED CARE AND PHYSICIAN VIEWS REGARDING PHYSICIAN-PATIENT RELATIONSHIPS AND CLINICAL DECISION MAKING

Physician Perceptions Regarding:

Physician-Patient Relationships

To get new patients, I generally must sign managed care contracts'

Because of managed care the number of patients in my practice has:

My patients have a great deal of confidence in physicians'

Do you spend much time responding to patient complaints?

Clinical Decision Making

Third party payers have little effect on how I treat my patients' Sometimes I must ignore my own clinical judgment and follow the directives of nonphysicians regarding patient care'

Because of managed care the number of diagnostic tests I order has:

Managed care has changed the individual physicians to whom I refer patients

Managed care has changed the specialties to which I refer patients

$\mathrm{N}$

'Scored 1-5, strongly disagree to strongly agree.

*p $<.05$

$* * \mathrm{p}<.01$

$* * * p<.001$

\section{Correlations \\ with}

Percentage

Patients from

Managed Care

Response

$0-24 \%$

from Managed Care

$25-49 \%$

50-74\% $75-100 \%$

Chi-square

[d.f.]

$.389 * * *$

$\begin{array}{crrrrc}\text { Increased } & 7.1 \% & 37.0 \% & 58.1 \% & 52.1 \% & 77.9^{* * *} \\ \text { No change } & 76.5 \% & 44.4 \% & 25.2 \% & 32.2 \% & {[6]} \\ \text { Decreased } & 16.5 \% & 18.5 \% & 16.8 \% & 15.8 \% & \\ & & & & & \\ \text { Yes } & 53.5 \% & 46.9 \% & 47.3 \% & 50.0 \% & 1.17 \\ \text { No } & 46.5 \% & 53.1 \% & 52.7 \% & 50.0 \% & {[3]}\end{array}$

$\begin{array}{crrrrc}\text { Increased } & 1.2 \% & 1.2 \% & 4.8 \% & 9.7 \% & 19.6^{* *} \\ \text { No change } & 81.7 \% & 63.4 \% & 66.1 \% & 66.9 \% & {[6]} \\ \text { Decreased } & 17.1 \% & 35.4 \% & 29.1 \% & 23.5 \% & \\ & & & & & \\ \text { Yes } & 72.1 \% & 79.3 \% & 84.5 \% & 89.7 \% & 13.0^{* *} \\ \text { No } & 27.9 \% & 20.7 \% & 15.5 \% & 10.3 \% & {[3]} \\ & & & & & \\ \text { Yes } & 57.0 \% & 52.5 \% & 56.0 \% & 58.6 \% & 0.8 \\ \text { No } & 43.0 \% & 47.5 \% & 44.0 \% & 41.4 \% & {[3]}\end{array}$

$-.090 *$

$.124 * *$

$-.148 * * *$

$46.5 \%$
82

81

$166 \quad 144$

473 
Typically, popular and professional discussions suggest that managed care leads to a dramatic reduction in the use of diagnostic tests. Our results suggest a more complex relationship between managed care and testing. Overall, and regardless of level of participation in managed care, more than two-thirds of physicians ( 69 percent) believe that managed care has had no impact on testing, although more believe it has decreased testing than increased it ( 26 percent versus 5 percent). However, physicians with higher levels of participation in managed care are more likely than those with lower levels of participation to believe it has increased testing and less likely to believe it has decreased testing.

Most respondent physicians ( 82 percent overall) believe that managed care has changed the individual physicians to whom they refer. This sentiment is directly related to degree of participation in managed care: 72 percent of those with one-quarter or less of patients from managed care believe that they have had to change the physicians to which they refer, compared to 90 percent of those with three-quarters or more of patients from managed care. Physicians are less likely to believe that managed care has changed the specialties to which they refer (although a majority do believe it has had an effect), and participation in managed care does not significantly affect their views on this issue.

\section{Work Settings}

Almost three-quarters ( 73 percent) of respondents overall claim that managed care has had no impact on the number of hospitals at which they have privileges. Ten percent say that managed care has decreased the number of hospitals at which they have privileges, while 16 percent say that it has increased their hospital privileges. The proportion who believe managed care has either increased or decreased privileges rises significantly from 6 percent among those with less than a quarter of patients from managed care to 37 percent among those with three-quarters or more of patients from managed care (Table 2).

As the percentage of patients from managed care increases, the likelihood of owning or renting one's office decreases significantly, as indicated by a small inverse correlation. It is nevertheless striking how many physicians own or rent their own offices even when they participate heavily in managed care; among those receiving three-fourths or more of their patients from managed care, almost half ( 46 percent) do so.
Similarly, participation in managed care modestly decreases the likelihood of owning one's diagnostic technology, as shown by another small inverse correlation.

\section{Work Conditions}

Physicians who participate most in managed care report less control over their work schedule and less satisfaction with their pay. Participation in managed care is positively correlated with agreement to the statement "I do not determine my work schedule," and inversely correlated with agreement to the statement, "By and large, I am paid what I want to be paid for my services."

\section{Satisfaction}

Physician satisfaction was measured by answers to three items, combined into one factor score (as described in the methods section). Physicians who are heavily involved in managed care are less satisfied, as indicated by a significant inverse correlation between satisfaction and the percentage of patients from managed care. We suspect that those with one-quarter to one-half of their patients from managed care have a base of patients for whom payment (via managed care contracts) is assured, if perhaps lower than desired, but escape some of the additional bureaucratic nuisances and restraints on their autonomy that managed care plans impose. Conversely, those with threequarters or more of their patients from managed care face the most restrictions and nuisances, while perhaps receiving somewhat lower incomes than their colleagues. ${ }^{18,19}$ However, further analysis (reported elsewhere) of the correlates of satisfaction suggests that participation in managed care need not lead to dissatisfaction if physicians retain clinical decisionmaking, control over their work and fee schedules, the ability to attract patients outside of managed care contracts, and the belief that their patients have confidence in physicians. ${ }^{24}$

\section{Multivariate Relationships}

In this section we look again at the impact of managed care on the same dependent variables, but this time using multivariate regressions controlling for age, sex, practice size, and specialty versus primary care. These regressions show whether the apparent impact of managed care in the bivariate analyses is spurious (i.e., attributable to these control variables). 
TABLE 2

BIVARIATE RELATIONSHIPS (CORRELATIONS OR CROSS TABULATIONS) BETWEEN PERCENTAGE OF PATIENTS IN MANAGED CARE AND PHYSICIAN VIEWS REGARDING WORK SETTINGS, WORK CONDITIONS, AND OVERALL SATISFACTION

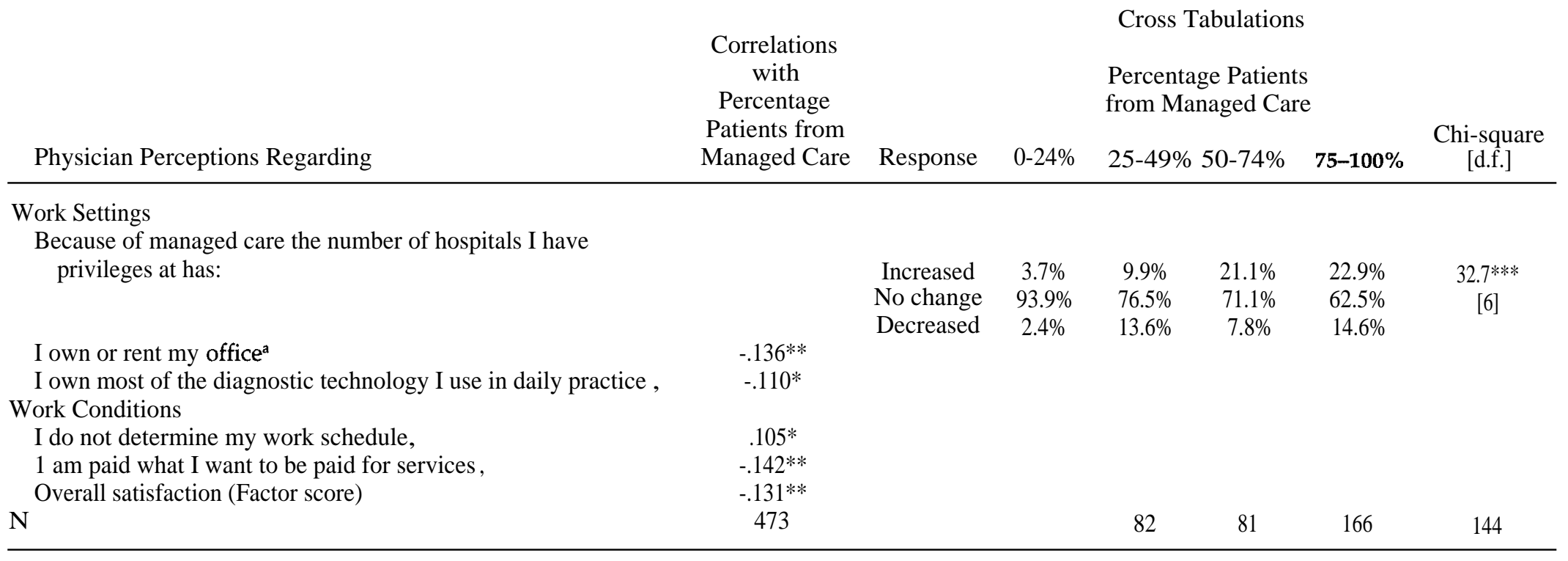

scored 1-5, strongly disagree to strongly agree.

$* \mathrm{p}<.05$

$* * p<.01$

$* * * \mathrm{p}<.001$ 
We also control for payment type, to see whether this might explain why managed care has the impact it does.

Some of these control variables are themselves related to participation in managed care, while others are not. Participation in managed care is unrelated to physicians' age or gender, but those in larger practices and those in primary care draw more of their patients from managed care. Physicians who participate most in managed care are more likely to be paid by capitation and less likely to be paid by their own fee-forservice schedule, but participation in managed care is not clearly related to payment by salary or by a third party's fee-for-service schedule. (Respondents were asked which of these four methods they were paid by, and answers were not mutually exclusive.)

\section{Physician Patient Relationships}

Adding the control variables did not change the relationships between participation in managed care and physician-patient relationships (Table 3). As in the bivariate analysis, greater participation in managed care predicts stronger agreement with the belief that one must sign managed care contracts to get patients and that managed care has increased patient load. And as in the bivariate analysis, greater participation in managed care predicts weaker agreement with the belief that patients have confidence in physicians but is not related to whether physicians feel they spend much time responding to patient complaints.

Whereas participation in managed care is related to three out of four aspects of physician-patient relation-

\section{TABLE 3}

\section{ORDINARY LEAST SQUARES (OLS) AND LOGISTIC REGRESSIONS OF PATIENT-PHYSICIAN RELATIONSHIPS ON PERCENTAGE OF PATIENTS IN MANAGED CARE AND BACKGROUND VARIABLES}

\section{Physician-Patient Relationships}

To Get Patients, Managed Care Patients Have $\quad$ Spend Much Time on Must Sign Contracts Increased Patients' Confidence in Doctors Patient Complaints

\begin{tabular}{|c|c|c|c|c|}
\hline & $\begin{array}{c}(\mathrm{OLS}) \\
\mathrm{bb}\end{array}$ & $\begin{array}{c}\text { (Logistic) } \\
\text { b }\end{array}$ & $\begin{array}{c}(\mathrm{OLS}) \\
\mathrm{b}\end{array}$ & $\begin{array}{c}\text { (Logistic) } \\
b\end{array}$ \\
\hline Patients in managed care $(\%)$ & $0.020 * * *$ & $0.021 * * *$ & $-0.004 * *$ & 0.000 \\
\hline Female' & -0.224 & -0.248 & $-0.315^{* *}$ & $0.673 * *$ \\
\hline Age & -0.004 & $-0.033 * *$ & -0.001 & 0.000 \\
\hline Practice size & $-0.004 *$ & 0.004 & -0.002 & -0.002 \\
\hline Primary care physician` & $-0.307 *$ & $0.566^{*}$ & 0.079 & 0.291 \\
\hline Paid by own fee schedule & -0.188 & 0.044 & 0.168 & -0.208 \\
\hline Paid by third party fee schedule & $0.456^{*}$ & 0.058 & 0.035 & 0.339 \\
\hline Paid by capitation & 0.187 & $1.235 * * *$ & -0.107 & -0.077 \\
\hline Paid by salaryc & -0.094 & 0.482 & 0.052 & -0.212 \\
\hline Intercept & $2731 * * *$ & -0.938 & $3.481 * * *$ & -0.298 \\
\hline Adjusted $\mathrm{R}^{2} /$ Gammad $_{\mathrm{d}}$ & 0.207 & 0.541 & 0.036 & 0.184 \\
\hline -2 Log Likelihood [d.f.] & & $536.2[9]$ & & 648.6 [9] \\
\hline $\mathrm{N}$ & 474 & 473 & 480 & 478 \\
\hline
\end{tabular}

'Coded as increased $=1$, no change or decreased $=0$.

'For OLS, $b=$ unstandardized regression coefficient; for logistic regressions $b=$ unstandardized $\log$ odds.

'Yes $=1$; no $=0$

${ }^{\mathrm{d}}$ Gammas for logistic regression are pseudo $\mathbf{R}^{2}$ estimates.

$* \mathrm{p}<.05$

$* * \mathrm{p}<.01$

$* * * \mathrm{p}<.001$ 
ships, no control variable is related to more than two aspects. Those in smaller practices, specialists, and those paid by a third party's fee schedule are most likely to believe that they must sign contracts, while younger physicians, primary care physicians, and those paid by capitation are most likely to believe that managed care increases patient load. (This last finding is not surprising, as under capitation income can be directly related to patient load.) Gender did not affect these two items, which deal with numbers of patients, but was the only variable (other than participation in managed care) that affected the two items measuring interactions with patients: females are substantially more likely to believe that they spend much time on patient complaints, while males are more likely to believe that their patients have confidence in physicians.

\section{Clinical Decision Making}

As with physician-patient relationships, adding the control variables did not change the relationship between managed care and clinical decision making. Again, greater participation in managed care predicted weaker agreement with the belief that "Third party payers have little effect on how I treat my patients" and stronger agreement with the belief that "Sometimes I must ignore my own clinical judgment and follow the directives of nonphysicians regarding patient care" (Table 4). As in the bivariate analyses, those who participated more heavily in managed care tended to agree more often that managed care led to increases in testing and changed the physicians to which they refer patients. However, participation in managed care had no impact on the belief that managed care had changed the specialties to which respondents refer.

As with physician-patient relationships, participation in managed care is the most consistently significant independent variable. The only other independent variable that significantly related to more than one dependent variable in this section was payment by one's own fee schedule. Those paid in this way were considerably less likely to report changes due to managed care in either the individual physicians or the specialties to which they referred. Apparently, regardless of the level of participation in managed care, physicians paid by fee-for-service remain more tied to traditional interdependent colleague networks, in which economic success still depends at least in part on referring to those who will make referrals back in return? ${ }^{\circ}$
Work Setting

As in the bivariate analysis, greater participation in managed care predicts stronger agreement with the belief that managed care has changed the number of hospitals at which one has privileges and weaker agreement with the statement "I own or rent my own office" (Table 5). (Because approximately equal numbers of physicians claimed that managed care had either increased or decreased the number of hospitals at which they had privileges, and because physicians may equally fear either change-an increase in hospitals means more time spent getting privileges and traveling between hospitals, while a decrease may mean having to work at less preferred hospitals-we combined these two groups in the regression analysis and compared them to those who reported no change.) In addition, payment according to a third party's fee-for-service schedule is a predictor of fewer changes in the number of hospitals at which one has privileges and of increased likelihood of owning or renting one's office. Males, those in smaller practices, and those either paid by their own fee schedule or not paid by salary report higher levels of owning or renting their own office; such individuals more closely match traditional models of medical practice, and are more likely to have both the need and the opportunity to have their own offices. For these variables, therefore, the effect of managed care operates along with the effects of other independent variables.

However, whereas in the bivariate analysis, participation in managed care was negatively related to owning one's diagnostic technology, in the multivariate analysis this effect disappears, while payment by a third party's fee schedule predicts a higher likelihood of ownership. In this case, therefore, payment type appears to explain the impact of managed care.

\section{Work Conditions}

Adding the control variables does not affect the relationship between participation in managed care and work conditions: Greater participation in managed care predicts less control over one's work schedule and satisfaction with pay (Table 5). However, as with work settings, payment type also affects work conditions. Those who are paid by either their own or a third party's fee schedule report the most control over their work schedule; as with work settings, such individuals are more likely to have both the need and the opportunity to do so. Not surprisingly, those paid by 
TABLE 4

\section{ORDINARY LEAST SQUARES (OLS) AND LOGISTIC REGRESSIONS OF CLINICAL DECISION MAKING ON PERCENTAGE OF PATIENTS IN MANAGED CARE AND BACKGROUND VARIABLES}

\begin{tabular}{|c|c|c|c|c|c|}
\hline & & & hical Decision $\mathrm{N}$ & king & \\
\hline & $\begin{array}{l}\text { Third Party } \\
\text { Payers Don't } \\
\text { Affect } \\
\text { Treatments }\end{array}$ & $\begin{array}{l}\text { Sometimes } \\
\text { Must Ignore } \\
\text { Clinical } \\
\text { Judgment }\end{array}$ & $\begin{array}{c}\text { Managed } \\
\text { Care } \\
\text { Increased } \\
\text { Diagnostic } \\
\text { Tests I Order' }\end{array}$ & $\begin{array}{c}\text { Managed } \\
\text { Care } \\
\text { Changed } \\
\text { Physicians To } \\
\text { Whom I Refer }\end{array}$ & $\begin{array}{c}\text { Managed } \\
\text { Care } \\
\text { Changed } \\
\text { Specialties To } \\
\text { Which I Refer }\end{array}$ \\
\hline & $\begin{array}{c}\text { (OLS) } \\
\mathrm{bb}\end{array}$ & $\begin{array}{c}(\mathrm{OLS}) \\
\mathrm{b}\end{array}$ & $\begin{array}{c}\text { (Logistic) } \\
\text { b }\end{array}$ & $\begin{array}{c}\text { (Logistic) } \\
\text { b }\end{array}$ & $\begin{array}{c}\text { (Logistic) } \\
\text { b }\end{array}$ \\
\hline Patients in managed care $(\%)$ & $-0.005^{*}$ & $0.006^{* *}$ & $0.038 * *$ & $0.017 * * *$ & -0.001 \\
\hline Female & $0.427 *$ & -0.146 & -0.377 & 0.479 & -0.025 \\
\hline Age & 0.001 & -0.007 & 0.002 & 0.015 & 0.011 \\
\hline Practice size & 0.004 & -0.003 & -0.007 & $-0.011 * *$ & -0.005 \\
\hline Primary care physician & -0.233 & 0.096 & 1.147 & 0.530 & 0.277 \\
\hline Paid by own fee schedule & 0.228 & -0.132 & -0.239 & $-0.856 * *$ & $-0.902 * * *$ \\
\hline Paid by third party fee schedule & -0.210 & 0.094 & 0.950 & -0.222 & -0.310 \\
\hline Paid by capitation ${ }^{c}$ & 0.128 & -0.114 & 0.840 & -0.067 & 0.274 \\
\hline Paid by salary & 0.154 & -0.140 & 0.603 & -0.299 & -0.118 \\
\hline Intercept & $2.819 * * *$ & $2.614 * * *$ & $-7.469 * * *$ & 0.571 & 0.275 \\
\hline Adjusted $R^{2} /$ Gammad & 0.027 & 0.010 & 0.620 & 0.413 & 0.288 \\
\hline -2 Log Likelihood [d.f.] & & & 159.4 [9] & 397.9 [9] & 617.2 [9] \\
\hline $\mathrm{N}$ & 478 & 480 & 468 & 476 & 471 \\
\hline $\begin{array}{l}\text { 'Coded as increased }=1 \text {, no change or } \\
\text { 'For OLS, } b=\text { unstandardized regressio } \\
\text { yes }=1 ; n 0=0\end{array}$ & $\begin{array}{l}\text { reased }=0 \text {. } \\
\text { oefficient; for lo }\end{array}$ & ic regressions b & standardized log & & \\
\hline $\begin{array}{l}{ }^{\mathrm{d}} \text { Gammas for logistic regression are } \mathrm{p} \\
{ }_{*} \mathrm{p}<.05 \\
* * \mathrm{p}<, 01 \\
* * * \mathrm{p}<.001\end{array}$ & do $R^{2}$ estimates. & & & & \\
\hline
\end{tabular}

their own fee schedule are most likely to be paid what they want for their work.

\section{Satisfaction}

As in the bivariate analysis, greater participation in managed care is a predictor of lower overall satisfaction. Younger physicians report more satisfaction, perhaps because managed care has been the norm for much of their lifetime; such physicians may have participated as patients in managed care plans from an early age, received their medical training in settings dominated by managed care, and assumed from the start of their medical career that they would work un- der managed care. Finally, those paid by their own fee schedule report more satisfaction, perhaps because such a payment system offers them additional economic and professional autonomy.

\section{CONCLUSIONS}

Maricopa County residents are almost 50 percent more likely than Americans in general to belong to a managed care plan. This high penetration of managed care means that, although some Arizona physicians practice under managed care out of choice, others have felt forced to do so-a situation that increasingly 
TABLE 5

\section{ORDINARY LEAST SQUARES (OLS) AND LOGISTIC REGRESSIONS OF WORK SETTING, CONDITIONS AND SATISFACTION ON PERCENTAGE OF PATIENTS IN MANAGED CARE AND BACKGROUND VARIABLES}

\begin{tabular}{|c|c|c|c|c|c|c|}
\hline & \multicolumn{3}{|c|}{ Work Setting } & \multicolumn{2}{|c|}{ Work Conditions } & Satisfaction \\
\hline & $\begin{array}{c}\text { Managed } \\
\text { Care } \\
\text { Changed } \\
\text { Hospital } \\
\text { Privileges' } \\
\text { (Logistic) } \\
\text { bb }\end{array}$ & $\begin{array}{l}\text { Own or } \\
\text { Rent My } \\
\text { Office } \\
\text { (OLS) } \\
\text { b }\end{array}$ & $\begin{array}{l}\text { Own My } \\
\text { Diagnostic } \\
\text { Equipment } \\
\text { (OLS) } \\
\text { b }\end{array}$ & $\begin{array}{l}\text { Do Not } \\
\text { Determine } \\
\text { My Work } \\
\text { Schedule } \\
\text { (OLS) } \\
\text { b }\end{array}$ & $\begin{array}{l}\text { Paid What } \\
\text { I Want } \\
\text { (OLS) } \\
\text { b }\end{array}$ & $\begin{array}{c}\text { (Factor } \\
\text { Score) } \\
\text { (OLS) } \\
\text { b }\end{array}$ \\
\hline Patients in managed care $(\%)$ & $0.023^{* * * *}$ & $-0.005^{*}$ & -0.004 & $0.005^{*}$ & $-0.007 * * *$ & $-0.005 * * *$ \\
\hline Female & -0.570 & $-0.382 *$ & -0.026 & 0.221 & 0.132 & -0.177 \\
\hline Age & -0.022 & -0.009 & 0.012 & -0.002 & -0.004 & $-0.013 * *$ \\
\hline Practice size & -0.005 & $-0.007 * * *$ & -0.003 & -0.003 & 0.001 & 0.002 \\
\hline Primary care physician & -0.060 & 0.114 & 0.156 & -0.110 & -0.021 & -0.050 \\
\hline Paid by own fee schedule & -0.482 & $0.569 * * *$ & 0.236 & $-0.382 * *$ & $0.464 * * *$ & $0.224 *$ \\
\hline Paid by third party fee schedule & $-0.567 * *$ & $0.987 * * *$ & $0.834 *$ & $-0.928 * * *$ & -0.173 & \\
\hline Paid by capitation ${ }^{c}$ & -0.081 & 0.031 & -0.031 & 0.122 & 0.197 & \\
\hline Paid by salary & -0.216 & $-0.606^{* *}$ & 0.606 & 0.186 & 0.196 & \\
\hline Intercept & $-1.750 *$ & $3.266^{* * *}$ & $1.516^{* * *}$ & $2.988 * * *$ & $3.090 * * *$ & $0.820 * *$ \\
\hline $\begin{array}{l}\text { Adjusted R²/Gammad } \\
2 \text { Log Likelihood [d.f.] }\end{array}$ & $\begin{array}{c}0.383 \\
496.6[9]\end{array}$ & 0.545 & 0.229 & 0.071 & 0.134 & 0.052 \\
\hline $\mathrm{N}$ & 467 & 468 & 473 & 482 & 480 & 476 \\
\hline $\begin{array}{l}\text { aCoded increase or decrease }=1 \text {, no cha } \\
\text { 'For OLS, } \mathrm{b}=\text { unstandardized regressio } \\
\text { yes }=1 ; \text { no }=0 \\
\text { 'Gammas for logistic regression are } \mathrm{p} \\
* \mathrm{p}<.05 \\
* * \mathrm{p}<.01 \\
* * * \mathrm{p}<.001\end{array}$ & $\begin{array}{l}=0 . \\
\text { efficient; for } \\
\text { lo } \mathrm{R}^{2} \text { estimate }\end{array}$ & istic regres & $\mathrm{b}=$ unstanda & dog odds. & & \\
\hline
\end{tabular}

faces physicians around the nation. It is therefore not too surprising that physicians in this survey consistently report that managed care has had significant and largely unpleasant effects on the practice of medicine. These effects are highly robust, surviving in all but one regression when several independent variables are entered into the equations. The data also suggest that payment type often affects physicians separately from the impact of participation in managed care per se. Other independent variables have surprisingly little impact, and no patterned impact.

Physicians believe that managed care has had a significant impact on their relationships with patients.
First, participation in managed care is directly related to physicians' belief that to get new patients, they must sign managed care contracts. We would, posit that this relationship is bidirectional: the more a physician participates in managed care, the more difficult it is for him or her to obtain patients through other sources, while the more physicians believe it is difficult to get new patients through other sources, the more likely they are to participate in managed care. Second, participation in managed care is directly related to reported increases in patient load. Physicians who work as salaried employees of managed care plans may find that the plans expect them to have 
more patients than is the norm for medical practices in their area, while those who are paid primarily through capitation may increase their patient loads to spread the risks should a few of their patients make heavy use of medical services. Third, participation in managed care is negatively related to the belief that one's patients have a great deal of confidence in physicians. We cannot tell from our data whether managed care actually erodes physician-patient relationships, but certainly physicians believe it does. One possible explanation for this is that under managed care, patients are often assigned to a given physician by an insurer. Consequently, physicians may assume that such patients cannot have as much confidence in their physicians as would patients who had freely chosen their physician. However, participation in managed care is unrelated to spending time on patient complaints, perhaps because managed care plans provide layers of bureaucracy that protect physicians from having to deal directly with patient complaints. Instead, gender emerged as the sole and highly significant predictor, with females much more likely than males to report that they spend much time on patient complaints.

Participation in managed care affects four out of the five measured aspects of clinical decision making. As participation increases, physicians are less likely to believe that third party payers don't affect treatment, and more likely to believe that they sometimes must ignore their clinical judgment, that managed care has increased their use of diagnostic tests, and that managed care has changed the individual physicians to whom they refer. These findings are logical consequences of the treatment protocols and financial incentives and disincentives that managed care plans typically establish.

Managed care significantly affects both physicians' work conditions and work settings. Those with higher percentages of patients from managed care are more likely to believe that managed care has changed the number of hospitals at which they have privileges (adding to the "hassle factor" that many physicians associate with managed care) and less likely to own or rent their own office. They are also less likely to determine their work schedule, be paid what they want for their services, or report overall satisfaction. All of these consequences reflect the nature of working for large bureaucratic institutions.

Administrators of managed care plans cannot afford to ignore the impact that participating in such plans has on physicians, for physicians are, of course, the backbone of any health care plan. When physicians are informed and satisfied, they are more likely to remain with a plan and more likely to provide high quality care, while their patients are also more likely to feel satisfied. ${ }^{21-23}$ Thus working with physicians to ameliorate the problems they associate with managed care may pay off in the long run.

The data from this study suggest several strategies that managed care plans can adopt to increase physician satisfaction. To reduce the "hassles" physicians associate with managed care, plans should consider giving physicians a greater role in negotiations regarding reimbursement, work schedules, patient loads, and which specialists and hospitals should be part of a plan's network. To strengthen physicians' belief in their clinical decision-making authority, plans also should involve physicians more actively in developing protocols regarding the use of diagnostic tests, medications, and specialist referrals; deciding what data should be collected for utilization reports and how that data should be used; and developing standards for reviewing physician applicants to the plan. Physicians who participate in such decisions and understand the basis on which they are made are more likely to support them and less likely to feel that their professional prerogatives are under attack. In addition, involving physicians in these decisions may enable physicians to limit some of the hassles they associate with managed care while reaping more of the rewards, further increasing physicians' satisfaction with participating in managed care and reducing the likelihood of turnover. Finally, managed care plans should work with physicians to ascertain why managed care patients have less confidence in physicians-or why managed care physicians believe this is so. Both managed care plans and physicians would benefit from these steps.

\section{REFERENCES}

Group Health Association of America, National Directory of HMOs. Washington, DC: Group Health Association of America, 1995.

2. Gonzalez, M.L. Socioeconomic Characteristics of Medical Practice 1994. Chicago: American Medical Association, 1994.

3. Gillis, K.D., and Emmons, D.W. Socioeconomic Characteristics of Medical Practice 1993. Chicago: American Medical Association, 1993.

4. McKinlay, J. "Introduction." The Milbank Quarterly 66, supplement 2 (1988): 1-9. 
5. McKinlay, J., and Arches, J. "Towards the Proletarianization of Physicians." International Journal of Health Services 15, no. 2 (1985): 161-95.

6. McKinlay, J.B., and Stoeckle, J.D. "Corporatization and the Social Transformation of Doctoring." International Journal of Health Services 18, no.2 (1989):191-205.

7. Stoeckle, J.D. "Reflections on Modern Doctoring." The Milbank Quarterly 66, suppl. 2 (1988): 76-91.

8. Hafferty, F.W., and McKinlay, J.B. "Conclusion: Cross-Cultural Perspectives on the Dynamics of Medicine as a Profession." In The Changing Medical Profession: A n International Perspective, edited by F.W. Hafferty and J.B. McKinlay. New York: Oxford University Press, 1993.

9. Light, D.W. "Countervailing Power: The Changing Character of the Medical Profession in the United States." In The Changing Medical Profession: An International Perspective, edited by F.W. Hafferty and J.B. McKinlay. New York: Oxford University Press, 1993.

10. Schneller E., Hughes, R., and Hood-Szivek, P. "The Future of Medicine." In New Leadership in Health Care Management: The Physician Executive, 2d edition, edited by W. Curry. Tampa, FL: The American College of Physician Executives, 1994.

11. Kletke, P.E., Emmons, D.W., and Gillis, K.D. "Current Trends in Physicians' Practice Arrangements: From Owners to Employees." Journal of the American Medical A ssociation 276, no. 7 (1996): 555-60.

12. Silverstein, G. "Physicians' Perceptions of Commercial and Medicaid Managed Care Plans: a Comparison." Journal of Health Politics, Policy, and Law 22, no. 1 (1997): 5-21.

13. Deckard, G.J. "Physician Responses to a Managed Environment: a Perceptual Paradox." Health Care Management Review 20, no. 1 (1995): 40-46.

14. Hadley, J., and Mitchell, J.M. "Effects of HMO Market Penetration on Physicians' Work Effort and Satisfaction." Health Affairs 16, no. 6 (1997):99-111.

15. Donelan, K., Blendon, R.J., Lundberg, G.D., et al. "The New Medical Marketplace: Physicians' Views." Health Affairs 16, no. 5 (1997): 139-148.

16. Edlin, M. "HMOs cry 'Eureka!"' Managed Healthcare (October 1994): 39-40.

17. Randolph, L., Seidman, B., and Pasko, T., et al. Physician Characteristics and Distribution in the United States. Chicago: American Medical Association, 1997.

18. Medical Group Management Association. Physician Compensation and Production Survey: 1995. Englewood, CO: Medical Group Management Association, 1995.

19. Simon, C.J., and Born, P.H. "Physician Earnings in a Changing Managed Care Environment." Health Affairs 15, no. 3 (1996): 124-33.

20. Freidson, E. Medical Work in America. New Haven, CT: Yale University Press, 1989.

21. Lichtenstein, R. "The Job Satisfaction and Retention of
Physicians in Organized Settings: a Literature Review." Medical Care Review 41, no. 2 (1984):139-179.

22. Linn, L.S., Brook, R.H., Clark, V.A., Davies, A.R., Fink, A., and Kosecoff, J. "Physician and Patient Satisfaction as Factors Related to the Organization of Internal Medicine Group Practices." Medical Care 23, no. 10 (1985): 1171-79.

23. Skolnik, N., Smith, D.R., and Diamond, J. "Professional Satisfaction and Dissatisfaction of Family Physicians." The Journal of Family Practice 37, no. 3 (1993): 257-63.

24. Warren, M.G., Weitz, R., and Kulis, S. "Physician Satisfaction in a Changing Health Care Environment: The Impact of Challenges to Professional Autonomy, Authority, and Dominance." Journal of Health and Social Behavior 39, no. 4 (1998): 356-367. 